\title{
Laboratory guideline for Turner syndrome
}

\author{
Daynna J. Wolff, PhD ${ }^{I}$, Daniel L. Van Dyke, PhD ${ }^{2}$, and Cynthia M. Powell, $M D^{3} ; A$ Working Group of \\ the ACMG Laboratory Quality Assurance Committee
}

\begin{abstract}
Disclaimer: This guideline is designed primarily as an educational resource for health care providers to help them provide quality medical genetic services. Adherence to this guideline does not necessarily ensure a successful medical outcome. This guideline should not be considered inclusive of all proper procedures and tests or exclusive of other procedures and tests that are reasonably directed to obtaining the same results. In determining the propriety of any specific procedure or test, the geneticist should apply his or her own professional judgment to the specific clinical circumstances presented by the individual patient or specimen. It may be prudent, however, to document in the patient's record the rationale for any significant deviation from this guideline.
\end{abstract}

\begin{abstract}
Turner syndrome is a disorder that has distinct clinical features and has karyotypic aberrations with loss of critical regions of the $\mathrm{X}$ chromosome. Several clinical guidelines on the diagnosis and management of patients with Turner syndrome have been published, but there is relatively little on the laboratory aspects associated with this disorder. This disease-specific laboratory guideline provides laboratory guidance for the diagnosis/study of patients with Turner syndrome and its variants. Because the diagnosis of Turner syndrome involves both a clinical and laboratory component, both sets of guidelines are required for the provision of optimal care for patients with Turner syndrome. Genet Med 2010:12(1):52-55.
\end{abstract}

Key Words: Turner syndrome, guideline, cytogenetics, mosaicism

A lthough clinical guidelines have addressed diagnosis of Turner syndrome, ${ }^{1-5}$ laboratory guidelines are lacking. This American College of Medical Genetics (ACMG) laboratory guideline provides information on appropriate pre- and postnatal diagnostic cytogenetic studies for Turner syndrome. Diseasespecific statements are intended to augment the current general ACMG Standards and Guidelines for Clinical Genetics Laboratories. Individual laboratories are responsible for meeting the Clinical Laboratory Improvement Amendments/College of American Pathologists quality assurance (QA) standards with respect to appropriate sample documentation, assay validation, general proficiency, and quality control measures.

This guideline is based on peer-reviewed scientific literature to the extent possible. However, there are relatively few articles published on laboratory practice for Turner syndrome, and

From the ${ }^{1}$ Department of Pathology and Laboratory Medicine, University of South Carolina, Charleston, South Carolina; ${ }^{2}$ Department of Laboratory Medicine and Pathology, Mayo Clinic, Rochester, Minnesota; and ${ }^{3}$ Department of Pediatric Genetics, University of North Carolina-Chapel Hill, Chapel Hill, North Carolina.

Daynna J. Wolff, PhD, Director, Clinical Cytogenetics and Molecular Genetics Professor, Department of Pathology and Laboratory Medicine, 165 Ashley Avenue, Suite 309, Charleston, SC 29425. E-mail: wolffd@musc.edu.

Disclosure: The authors declare no conflict of interest.

Submitted for publication October 16, 2009

Accepted for publication October 16, 2009.

DOI: $10.1097 /$ GIM.0b013e3181c684b2 hence expert consensus opinion was elicited to obtain best practices. The guideline was reviewed extensively by select experts on Turner syndrome, including Cytogeneticists and Clinical Geneticists, the ACMG Cytogenetic subcommittee of the Laboratory QA Committee, the QA Committee, and the ACMG Board of Directors. In addition, the document was vetted by the entire ACMG membership before adoption as a supplement to the ACMG Laboratory Standards and Guidelines.

\section{BACKGROUND ON TURNER SYNDROME}

\section{Chromosome locus}

A majority of genes associated with the physical features observed in Turner syndrome are located on Xp (Xp11.2-p22) loci contributing to ovarian function reside in Xq (Xq24). ${ }^{7}$

\section{Disease incidence and karyotypic finding}

The disease incidence is approximately 1 in 2500 liveborn females. A 45 , X karyotype is observed in $\sim 1 \%$ to $2 \%$ of conceptuses, $10 \%$ of miscarriages and $1 \%$ of stillbirths. Greater than $99 \%$ of 45 , X conceptuses result in spontaneous loss, usually before 28 weeks. The reason why $\sim 1 \%$ survive to term with relatively minor somatic abnormalities is not known, although it has been hypothesized that this is due to undetected mosaicism for a cell line with all or part of a second sex chromosome..$^{8,9}$

\section{Karyotype findings associated with Turner syndrome}

Prenatal. Approximately $1 \%$ to $2 \%$ of conceptuses have a 45 , X karyotype. These fetuses typically have ultrasound findings such as cystic hygroma or nuchal thickening. A majority of cases with mosaicism for a $45, \mathrm{X}$ cell line and a cell line with a second structurally normal sex chromosome result in the birth of a child with a normal phenotype. ${ }^{10,11}$

Postnatal. Apparently nonmosaic monosomy $\mathrm{X}$ is found in $\sim 45 \%$ of patients with Turner syndrome postnatally. A structural chromosome abnormality or mosaicism for $45, \mathrm{X}$ and another cell line is found in the lymphocytes of the remaining patients with Turner syndrome (Table 1). 
Table 1 Turner syndrome karyotypes

\begin{tabular}{lc}
\hline Karyotype & $\begin{array}{c}\text { Percentage of TS } \\
\text { cases }^{12-14}(\%)\end{array}$ \\
\hline $45, \mathrm{X}$ & 45 \\
$46, \mathrm{X}, \mathrm{i}(\mathrm{X})(\mathrm{q} 10) \mathrm{w} /$ or w/o 45,X & $15-18$ \\
$46, \mathrm{X},+$ mar or $+\mathrm{r}$ w/ or w/o 45,X & $7-16$ \\
$45, \mathrm{X} / 46, \mathrm{XX}$ or 45,X/47,XXX & $7-16$ \\
$46, \mathrm{X}, \mathrm{del}(\mathrm{Xp}) \mathrm{w} /$ or w/o 45,X & $2-5$ \\
$46, \mathrm{XY}$ or 46,X,del(Y) or 46,X,r(Y) w/ 45,X & $6-11$ \\
Others & $2-8$ \\
\hline
\end{tabular}

\section{Brief clinical description}

The features of Turner syndrome include characteristic physical features and complete or partial absence of the second sex chromosome. Phenotypic features vary widely but commonly include short stature, ovarian failure, edema of hands or feet, nuchal folds, left-sided cardiac anomalies, low hairline, low set ears, small mandible, cubitus valgus, nail hypoplasia, hyperconvex nails, multiple pigmented nevi, characteristic facies, short fourth metacarpal, and high arched palate. Females with short stature and deletion of the distal region of $\mathrm{Xp}$ including the SHOX gene are generally not diagnosed with Turner syndrome. Likewise, individuals with deletions of Xq24 with primary or secondary amenorrhea without short stature are typically diagnosed with premature ovarian failure. ${ }^{15}$

\section{Mode of inheritance}

Turner syndrome is sporadic. A majority of cases ascertained prenatally have a 45,X karyotype. Paternal nondisjunction accounts for $\sim 70 \%$ of liveborn cases with a $45, X .{ }^{16-17}$

\section{Ethnic association}

Turner syndrome is seen in all ethnic groups.

\section{Special testing considerations}

A differential diagnosis that includes Turner syndrome must take into consideration phenotypic features in combination with karyotypic findings. The phenotype varies greatly, therefore, both laboratory and clinical factors must be considered before a diagnosis may be rendered. Mental retardation is not a feature of Turner syndrome. The only sex chromosome structural abnormalities likely to cause mental retardation are a ring $\mathrm{X}$ chromosome with loss of XIST gene function and certain X-autosome translocations.

\section{Presence of $Y$ chromosome material}

Mosaicism for a cell line with a normal or abnormal $\mathrm{Y}$ chromosome is identified in $6 \%$ to $11 \%$ of patients with Turner syndrome with standard cytogenetic techniques. Identification of $\mathrm{Y}$ chromosome material in females with Turner syndrome is important because of the risk of gonadoblastoma. ${ }^{18}$ A gonadoblastoma is a neoplasm composed of germ cells and sex cord elements with an excellent prognosis if detected early. However, gonadoblastoma can progress to dysgerminoma with metastatic potential. A gonadoblastomasusceptibility locus has been proposed for the pericentromeric region of the Y chromosome. ${ }^{19-20}$ The neoplasm does not appear to correlate with the presence of $S R Y$.
Occult Y chromosome mosaicism detected by techniques other than standard cytogenetics in Turner syndrome varies by study and with methodology used. ${ }^{13,21-25}$ A meta-analysis of studies reporting a total of 541 patients with Turner syndrome without $\mathrm{Y}$ chromosome material on routine cytogenetic analysis found 5\% mosaicism for a Y-containing cell line using molecular techniques (Southern blot and/or polymerase chain reaction [PCR]). The percentage of patients with Y chromosome mosaicism (by molecular or standard cytogenetic techniques) was $8 \%$, and, of these, $12 \%$ had gonadoblastoma. Detection of occult $\mathrm{Y}$ mosaicism in 45,X subjects using interphase fluorescent in situ hybridization (FISH) with a probe for the Y centromere (DYZ3) has been reported to range from $0 \%$ to $4 \% .{ }^{24,25}$

\section{Prenatal testing}

Monosomy $\mathrm{X}$ is frequently identified by prenatal diagnostic procedures. Ultrasound findings can include nuchal translucency, cystic hygroma, coarctation of the aorta and/or other left-sided heart defects, brachycephaly, renal anomalies, polyhydramnios, oligohydramnios, and growth retardation. Abnormal prenatal serum marker screening results with elevated levels of human chorionic gonadotropin and inhibin and slightly decreased levels of alpha fetoprotein and unconjugated estriol are associated with an increased likelihood of a Turner syndrome diagnosis. ${ }^{27,28}$ Prenatal diagnosis may indicate a karyotype consistent with a diagnosis of Turner syndrome; however, the phenotype of the individual cannot be predicted based on the chorionic villus or amniotic fluid cell karyotype, FISH, or microarray results. In the absence of abnormal prenatal ultrasound findings, girls with incidental prenatal karyotype findings associated with Turner syndrome have a less severe phenotype with fewer physical abnormalities compared with those diagnosed due to abnormal ultrasound findings. Because the constitutional karyotype of individuals with prenatal ascertainment of sex chromosome complements consistent with Turner syndrome is uncertain, postnatal chromosome studies are recommended. Failure to confirm the prenatal findings with a blood karyotype should prompt consideration of analysis of another tissue such as buccal or skin cells.

Females with monosomy $\mathrm{X}$ or a structurally abnormal $\mathrm{X}$ chromosome may manifest X-linked recessive disorders; when an X-linked recessive disorder is identified in a female, karyotyping is warranted.

The detection of a low level of $45, \mathrm{X}$ cells $(<10 \%)$ during routine cytogenetic analysis of peripheral blood or bone marrow from an adult female can be difficult to interpret. It has been well documented that there is age-related loss of the $\mathrm{X}$ chromosome. ${ }^{29}$ Laboratories should have procedures for an evaluation that assists with the determination of the significance of 45 , X cells detected in women based on age, and for reporting, when appropriate.

\section{GUIDELINE}

\section{Methodological considerations}

\section{Prenatal diagnosis}

Refer to the ACMG Laboratory Standards and Guidelines (www.acmg.net, 2008) for general laboratory recommendations on prenatal diagnosis.

When multiple cells from a single culture are identified with a 45,X karyotype, a moderate work-up is warranted. This includes examination of an additional 20 cells from cultures other than the one with the initial finding or 12 colonies from coverslips other than the one with the abnormality. ${ }^{30}$ 
Additional cells or colonies should be evaluated when a structurally abnormal X chromosome is identified to determine if the finding is true or pseudomosaicism. Depending on the aberration (e.g., marker chromosome and unbalanced or balanced structural abnormality in single or multiple cultures), guidelines for moderate or extensive evaluation would apply. ${ }^{30}$

When an apparent sex chromosome marker is identified in a fetus with only a single $\mathrm{X}$ chromosome, a moderate (if found in a single cell in culture or on a single coverslip) or extensive work-up (if found in multiple cells in a single culture or multiple colonies from a single coverslip) is recommended. ${ }^{30}$

If the marker is found in every cell or is mosaic, additional testing to identify the origin of the marker using FISH with $\mathrm{X}$ and $\mathrm{Y}$ centromere probes is recommended.

When a small ring or small marker chromosome is determined to be derived from the $\mathrm{X}$ chromosome, FISH with a probe for the XIST gene should be performed. Depending on the size and content of the small ring/marker, lack of the XIST locus may be associated with a more severe phenotype that includes mental retardation. ${ }^{26,31}$

For interphase analysis using $\mathrm{X}$ and $\mathrm{Y}$ centromere probes, normal cutoff values should be established for a second $\mathrm{X}$ chromosome signal using normal male controls, and for a Y chromosome signal using normal female controls. ${ }^{25}$ See section E10 for information on establishment of a normal cut-off value (ACMG Standards and Guidelines, www.acmg.net, 2008).

\section{Postnatal studies}

Cases being studied for possible Turner syndrome, in which mosaicism is common, should include a minimum of 30 cells counted, unless mosaicism is documented within the first 20 cells. When low-level mosaicism for $45, \mathrm{X}$ is detected, the age of the female should be taken into consideration to ensure that the $45, \mathrm{X}$ cell line is not due to age-related loss. ${ }^{29}$

Cytogenetic study of a second tissue (e.g., skin biopsy for cell culture or buccal smear for FISH) should be considered in individuals with a 46,XX karyotype only if there is a high level of suspicion for Turner syndrome based on phenotype. Consultation with the referring physician is recommended to determine whether a second tissue should be studied.

Additional studies are warranted if a 30-cell analysis reveals an apparently nonmosaic $45, \mathrm{X}$ karyotype. In patients without virilizing features with a nonmosaic 45,X karyotype, FISH analysis using $\mathrm{X}$ and $\mathrm{Y}$ probes can identify low-level sex chromosome mosaicism. ${ }^{25}$ Although the frequency of gonadoblastoma in Turner syndrome with occult Y chromosome mosaicism without evidence of virilization is not fully appreciated, additional studies are recommended in these cases to help prevent a potential life-threatening cancer. ${ }^{32}$

FISH with $\mathrm{X}$ and $\mathrm{Y}$ centromere probes should be performed on a minimum of 200 interphase cells. An appropriate database should be created and normal cutoff values should be established for a Y chromosome signal using normal female controls. $^{25}$ See section E.10 for information on establishment of a normal cutoff value (ACMG Standards and Guidelines, www. acmg.net, 2008).

If the patient reveals an apparently nonmosaic 45,X karyotype and has clitoromegaly or other masculinizing features, it is very likely that there is mosaicism for a $\mathrm{Y}$ chromosomecontaining cell line. ${ }^{15}$ FISH with probes for the $\mathrm{X}$ and $\mathrm{Y}$ centromeres should be performed on a minimum of 200 cells to detect low-level Y chromosome mosaicism. Given the high suspicion for Y chromosome material, study of a second cell type may be warranted. Consultation with the referring physician is recommended.
Additional studies should be performed when a small ring/ marker chromosome is identified. This is the same as for section "Prenatal Diagnosis" earlier. Note that there is not always a correlation between the presence of XIST in the ring and cognitive phenotype. ${ }^{33}$ The size of the active ring appears to have a greater correlation with outcome. ${ }^{34-36}$

\section{Interpretation and reporting}

The following elements should be included in the report, in addition to the items described in the current general Standards and Guidelines.

Referral for genetic counseling and evaluation by a clinical geneticist and/or other appropriate health care provider. ${ }^{15,37}$

When a karyotype consistent with Turner syndrome is found prenatally, postnatal chromosome analysis is recommended to document the child's karyotype. ${ }^{38}$

\section{ALTERNATIVE TESTING METHODS}

\section{PCR}

For detection of Y-chromosomal material using PCR, a high rate of false-positive results has been reported. ${ }^{25,39}$ Thus, caution should be exercised in the interpretation of Y-chromosome sequence PCR. FISH confirmation using a Y centromere probe after a positive PCR result is prudent.

Genomic copy number microarray studies can be used to further characterize abnormalities that are detected by cytogenetic studies. However, microarrays may not detect low-level mosaicism and should not be used as the initial screen for sex chromosome abnormalities.

\section{ACKNOWLEDGMENTS}

The authors thank Virginia Proud and the Professional Practice and Guidelines Committee Chairs, Rick Martin and Helga Toriello, for their input on the clinical significance of laboratory findings associated with Turner syndrome.

\section{REFERENCES}

1. Bondy CA. Turner Syndrome Study Group. J Clin Endocrinol Metab 2007; 92:10-25

2. Saenger P, Wikland KA, Conway GS, et al; Fifth International Symposium on Turner Syndrome. Recommendations for the diagnosis and management of Turner syndrome. J Clin Endocrinol Metab 2001;86:3061-3069.

3. Frias JL, Davenport ML; Committee on Genetics, and the Section on Endocrinology. American Academy of Pediatrics Clinical Report. Health supervision for children with Turner syndrome. Pediatrics 2003;111:692-702.

4. Seaver LH, Irons M; ACMG Professional Practice and Guidelines Committee. ACMG Practice Guideline: genetic evaluation of short stature. Genet Med 2009; 11:465-470

5. Seaver LH, Irons M. ACMG practice guideline: genetic evaluation of short stature. Genet Med 2009:11:465-470.

6. Zinn AR, Tonk VS, Chen Z, et al. Evidence for a Turner syndrome locus or loci at Xp11.2-p22.1. Am J Hum Genet 1998;63:1757-1766.

7. Schlessinger D, Herrera L, Crisponi L, et al. Genes and translocations involved in POF. Am J Med Genet 2002;111:328-333.

8. Hook EB, Warburton D. The distribution of chromosomal genotypes associated with Turner's syndrome: livebirth prevalence rates and evidence for diminished fetal mortality and severity in genotypes associated with structural X abnormalities or mosaicism. Hum Genet 1983;64:24-27.

9. Held KR, Kerber S, Kaminsky E, et al. Mosaicism in 45, X Turner syndrome: does survival in early pregnancy depend on the presence of two sex chromosomes? Hum Genet 1992;88:288-294.

10. Koeberl DD, McGillivray B, Sybert VP. Prenatal diagnosis of 45,X/46,XX mosaicism and 45,X: implications for postnatal outcome. Am J Hum Genet 1995;57:661-666.

11. Chang HJ, Clark RD, Bachman H. The phenotype of $45, X / 46, X Y$ mosaicism: an analysis of 92 prenatally diagnosed cases. Am J Hum Genet 1990;46:156-167.

12. Sybert VP, McCauley E. Turner's syndrome. N Engl J Med 2004;351:12271238 . 
13. Jacobs $\mathrm{P}$, Dalton $\mathrm{P}$, James $\mathrm{R}$, et al. Turner syndrome: a cytogenetic and molecular study. Ann Hum Genet 1997;61:471-483.

14. Gardner RJ, Sutherland GR. Chromosome abnormalities and genetic counseling, 3rd ed. New York, NY: Oxford Press, 2004.

15. Bondy CA; Turner Syndrome Study Group. Care of girls and women with Turner syndrome: a guideline of the Turner Syndrome Study Group. J Clin Endocrinol Metab 2007;92:10-25.

16. Mathur A, Stekol L, Schatz D, MacLaren NK, Scott ML, Lippe B. The parental origin of the single $\mathrm{X}$ chromosome in Turner syndrome: lack of correlation with parental age or clinical phenotype. Am J Hum Genet 1991;48:682-686.

17. Skuse DH, James RS, Bishop DVM, et al. Evidence from Turner's syndrome of an imprinted X-linked locus affecting cognitive function. Nature 1997; 387:705-708.

18. Cools M, Drop SL, Wolffenbuttel KP, Oosterhuis JW, Looijenga LH. Germ cell tumors in the intersex gonad: old paths, new directions, moving frontiers. Endocr Rev 2006;27:468-484.

19. Tsuchiya K, Reijo R, Page DC, Disteche CM. Gonadoblastoma: molecular definition of the susceptibility region on the Y chromosome. Am J Hum Genet 1995;57:1400-1407.

20. Lau YF. Gonadoblastoma, testicular and prostate cancers, and the TSPY gene. Am J Hum Genet 1999;64:921-927.

21. Kokova M, Siegel SF, Wenger SL, Lee PA, Trucco M. Detection of Y chromosome sequences in Turner's syndrome by Southern blot analysis of amplified DNA. Lancet 1993;342:140-143.

22. Gravholt CH, Fedder J, Naeraa RW, Müller J. Occurrence of gonadoblastoma in females with Turner syndrome and Y chromosome material: a population study. J Clin Endocrinol Metab 2000;85:3199-3202.

23. Lopez M, Canto P, Aguinaga M, et al. Frequency of Y chromosomal material in Mexican patients with Ullrich-Turner syndrome. Am J Med Genet 1998;76:120-124.

24. Hanson L, Bryman I, Janson PO, Jakobsen AM, Hanson C. Fluorescence in situ hybridization analysis and ovarian histology of women with Turner syndrome presenting with Y-chromosomal material: a correlation between oral epithelial cells, lymphocytes and ovarian tissue. Hereditas 2002;137: $1-6$.

25. Wiktor AE, Van Dyke DL. Detection of low level sex chromosome mosa- icism in Ullrich-Turner syndrome patients. Am J Med Genet 2005;138A: 249-261.

26. Van Dyke DL, Wiktor A, Palmer CG, Miller DA, et al. Ullrich-Turner syndrome with a small ring $\mathrm{X}$ chromosome and presence of mental retardation. Am J Med Genet 1992;43:996-1005.

27. Wenstrom KD, Chu DC, Owen J, Boots L. Maternal serum-fetoprotein and dimeric inhibin A detect aneuploidies other than Down syndrome. Am J Obstet Gynecol 1998;179:966-970

28. Ruiz C, Lamm F, Hart PS. Turner syndrome and multiple-marker screening. Clin Chem 1999;45:2259-2261.

29. Russell LM, Strike P, Browne CE, Jacobs PA. X chromosome loss and ageing. Cytogenet Genome Res 2007;116:181-185.

30. Hsu LY, Benn PA. Revised guidelines for the diagnosis of mosaicism in amniocytes. Prenat Diagn 1999;19:1081-1090.

31. Wolff DJ, Brown CJ, Schwartz S, Duncan AM, Surti U, Willard HF. Small marker X chromosomes lack the $\mathrm{X}$ inactivation center: implications for karyotype/phenotype correlations. Am J Hum Genet 1994;55:87-95.

32. Mazzanti L, Cicognani A, Baldazzi L, et al. Gonadoblastoma in Turner syndrome and Y-chromosome-derived material. Am J Med Genet 2005;135: $150-154$.

33. Turner C, Dennis NR, Skuse DH, Jacobs PA. Seven ring (X) chromosomes lacking the XIST locus, six with an unexpectedly mild phenotype. Hum Genet 2000;106:93-100

34. Dennis N, Coppin B, Turner C, Skuse D, Jacobs PA. A clinical, cytogenetic and molecular study of 47 females with r(X) chromosomes. Ann Hum Genet 2000;64:277-293.

35. Kuntsi J, Skuse D, Elgar K, Morris E, Turner C. Ring-X chromosomes: their cognitive and behavioural phenotype. Ann Hum Genet 2000;64:295-305.

36. Migeon BR, Luo S, Stasiowski BA, Jani M, et al. Deficient transcription of $\mathrm{XIST}$ from tiny ring $\mathrm{X}$ chromosomes in females with severe phenotypes. Proc Natl Acad Sci USA 1993:90:12025-12029.

37. Loscalzo ML, Bondy CA, Beisecker B. Issues in prenatal counseling and diagnosis in Turner syndrome. Int Congr Ser 2006;1298:26-29.

38. Gravholt CH, Juul S, Naeraa RW, Hansen J. Prenatal and postnatal prevalence of Turner's syndrome: a registry study. BMJ 1996;321:16-21.

39. Nishi MY, Domenice S, Medeiros MA, Mendonca BB, Billerbeck AE. Detection of $\mathrm{Y}$-specific sequences in 122 patients with Turner syndrome: nested PCR is not a reliable method. Am J Med Genet 2002;107:299 -305. 